\title{
COMMUNICATIONS
}

\section{Wideband monopole antenna with dual band rejection characteristics}

\author{
Susmita Bala ${ }^{1}$, P. Soni Reddy ${ }^{2}$, \\ Sushanta Sarkar ${ }^{2}$, Partha Pratim Sarkar ${ }^{2}$
}

\begin{abstract}
A wideband printed monopole antenna with two rejection bands is proposed in this article. The antenna provides a wideband from $5.4 \mathrm{GHz}$ to $17.2 \mathrm{GHz}$ with two rejection bands covering 6.9 to $7.4 \mathrm{GHz}$ and 8.3 to $9.2 \mathrm{GHz}$ with two peak notch frequencies of $7.2 \mathrm{GHz}$ and $8.6 \mathrm{GHz}$ respectively. Tested peak gain at two peak notch frequencies of $7.2 \mathrm{GHz}$ and 8.6 $\mathrm{GHz}$ are $2.5 \mathrm{dBi}$ and $-1.5 \mathrm{dBi}$ respectively. These two rejection bands are effectively used to avoid undesired intrusion from the $\mathrm{C}$ band and the $\mathrm{X}$ band. The lower rejection band has been realized by cutting an open ring circular slot on the metal patch whereas $\mathrm{U}$ like slot has been inserted on the ground plane just beneath the feed line to achieve the upper rejection band. Simulated and tested $S_{11}$ parameter, gain, radiation efficiency, E-H radiation patterns, and surface currents of the antenna are presented here. The antenna uses small dimensions and it is very simple to design. The proposed antenna confirms that it is useful for short-range and fast data communication systems.
\end{abstract}

Keywords: printed monopole antenna, two rejection bands, radiation efficiency, radiation patterns

\section{Introduction}

The demand for miniaturized broadband antennas with band rejection characteristics increases day by day. To avoid interferences of existence different wireless application bands (like WLAN, WiMAX, C band, $\mathrm{X}$ band, etc). with the broadband applications, an antenna with band rejection characteristics is of high demand. A very popular and easy way to achieve band rejection characteristics is to introduce different shapes of slots, parasitic elements, strips, and resonators on the radiating patch and also the ground plane of the antenna which were previously reported in various articles.
Two notch bands have been achieved by embedding four circular stubs on the metal patch and two open circular rings on the ground plane are reported in [1]. Two $\mathrm{W}$-type slots are used for two band notches in [2]. Ulike monopole antenna uses two $\mathrm{T}$ slots on the two sides of the U patch and two rectangular SRR (split-ring resonator) placed at two sides of the feed line to obtain twonotch frequencies covering WiMAX and WLAN band in [3]. A new technique of sticking a patch on the available substrate to obtain two notch bands in WLAN and ITU band is reported in [4]. A co-planar waveguide feed circular patch antenna was suggested for two rejection band applications in [5]. It consists of a stub and a parasitic element to achieve two-band notches in the WLAN and
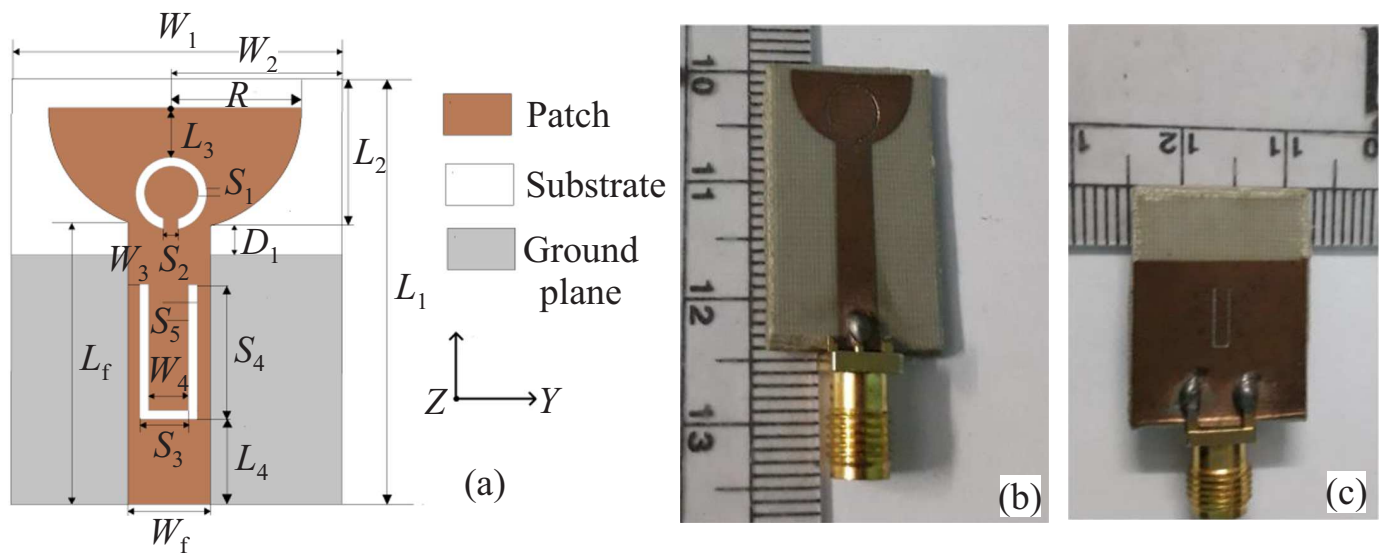

Fig. 1. Showing: (a) - details of the proposed antenna, (b) and (c) - snapshots of the proposed antenna

\footnotetext{
${ }^{1}$ Depatrment of Electronics, Vidyasagar University, Midnapore, West Bengal, India susmitabala@mail.vidyasagar.ac.in, ${ }^{2}$ Depatrment of DETS, Kalyani University, Kalyani, West Bengal, India p.sonireddy@gmail.com, sushantasarkar@aol.com, and parthabe91@yahoo.co.in

https://doi.org/10.2478/jee-2021-0037, Print (till 2015) ISSN 1335-3632, On-line ISSN 1339-309X

(C) This is an open access article licensed under the Creative Commons Attribution-NonCommercial-NoDerivs License (http: //creativecommons.org/licenses/by-nc-nd/3.0/).
} 
Table 1. Antenna dimensions in $\mathrm{mm}$

\begin{tabular}{ccccccccccccccccc}
\hline$w_{1}$ & $w_{2}$ & $w_{3}$ & $w_{4}$ & $w_{\mathrm{W} f}$ & $L_{1}$ & $L_{2}$ & $L_{3}$ & $L_{4}$ & $L_{\mathrm{L} f}$ & $S_{1}$ & $S_{2}$ & $S_{3}$ & $S_{4}$ & $S_{5}$ & $D_{1}$ & $R$ \\
16 & 8 & 0.8 & 1 & 3.4 & 24 & 7.5 & 0.9 & 7.6 & 17.24 & 0.4 & 0.5 & 1.4 & 6.4 & 0.4 & 0.75 & 6 \\
\hline
\end{tabular}
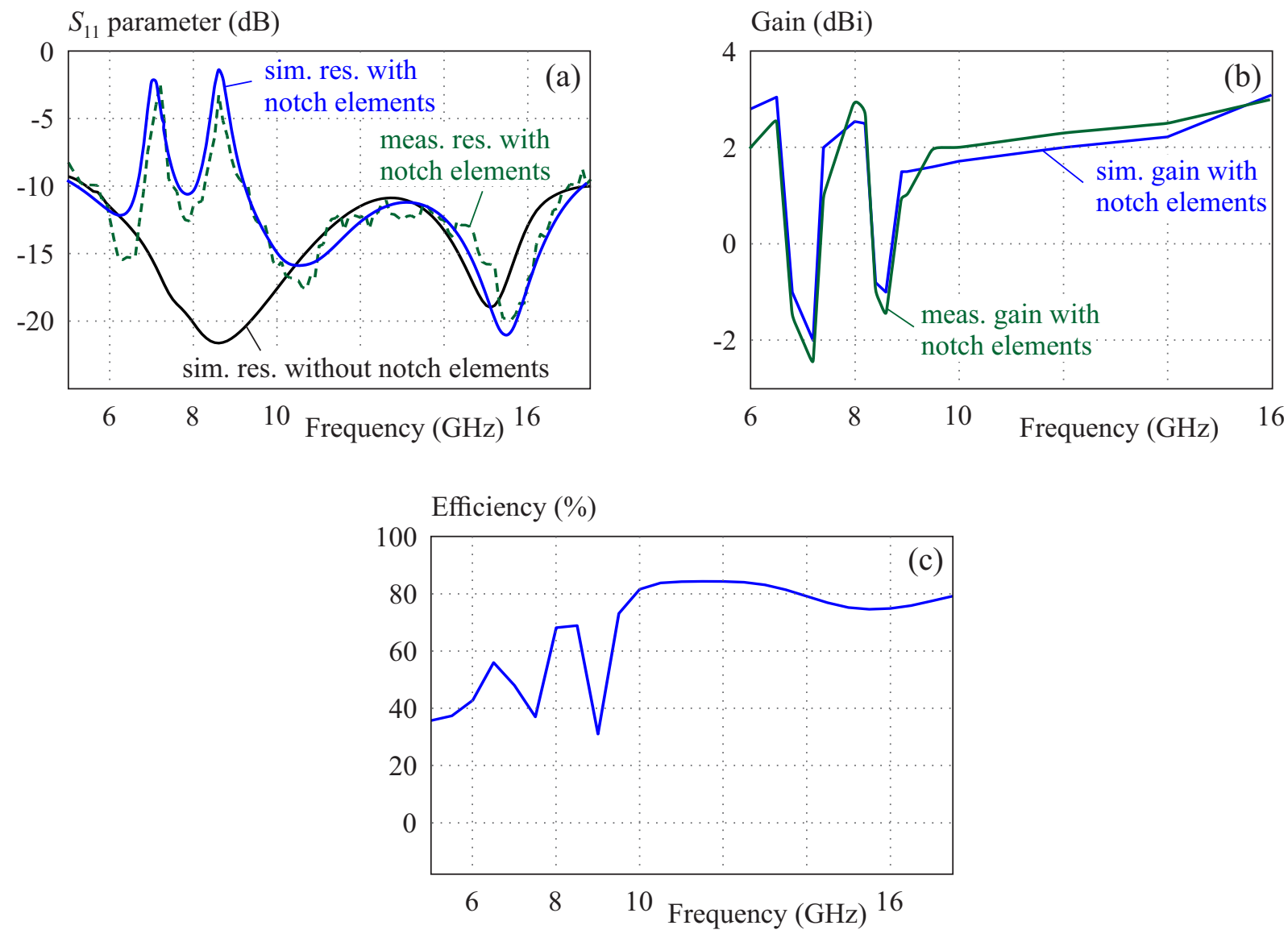

Fig. 2. Showing: (a) $-S_{11}$, (b) the gain, and (c) - the simulated efficiency plot

$\mathrm{X}$ band. A semi-annular ring-like antenna associate with a U-like radiator obtains two notch bands in WiMAX and WLAN applications and was informed in [6]. Two notch bands were obtained by embedding a U-type slot in the ground plane and inserting an open ring slot in the patch was reported in [7]. Two rectangular open ring resonators were placed on the patch of the antenna to achieve two notch bands of 3.40 to $3.48 \mathrm{GHz}$ and 5.40 to $5.98 \mathrm{GHz}$ in [8]. A tree- like antenna achieves notch characteristics using a rectangular resonator in the metal patch and using an additional spiral structure in the feed line [9]. Two short-circuited resonators were used for two notch bands and were informed in [10].

In this article, a simple and small size printed broadband monopole antenna with two rejection bands is proposed. The antenna consists of a half-circular metal patch with two-notch elements. Adjusting the positions and dimensions of the two-notch elements, two stop bands are achieved in the $\mathrm{C}$ band and the $\mathrm{X}$ band.

\section{Antenna design}

The geometry details of the proposed antenna with a $\mathrm{U}$ and an open ring circular notch elements is shown in Fig. 1.a. The antenna is printed on a substrate of Arlon DK with a thickness of $1.58 \mathrm{~mm}$ and a relative permittivity of 2.2 with a loss tangent of. 0009. The antenna has an area of $24 \times 16 \mathrm{~mm}^{2}$ and has a $16.5 \times 16 \mathrm{~mm}^{2}$ ground plane. It consists of a semi-circular metal patch with a radius of $6 \mathrm{~mm}$ as shown in Fig. 1(a). The length and width $\left(L_{\mathrm{f}}\right.$ and $\left.W_{\mathrm{f}}\right)$ of the feed line are $17.24 \mathrm{~mm}$ and $3.4 \mathrm{~mm}$ respectively to attain its matching resistance of $50 \Omega$. The distance between the metal patch and the ground plane is $0.75 \mathrm{~mm}$. An open ring slot of width $\left(S_{1}\right)$ $0.4 \mathrm{~mm}$ is inserted on the metal patch and a U-like slot of width $\left(S_{5}\right) 0.4 \mathrm{~mm}$ is placed at the truncated ground plane just beneath the feed line as shown in Fig. 1(a) to achieve notch characteristics. The dimensions of the proposed antenna with two notch elements are listed in Tab. 1. Snapshots of the proposed antenna are shown in Fig. 1(b) and Fig. 1(c). 

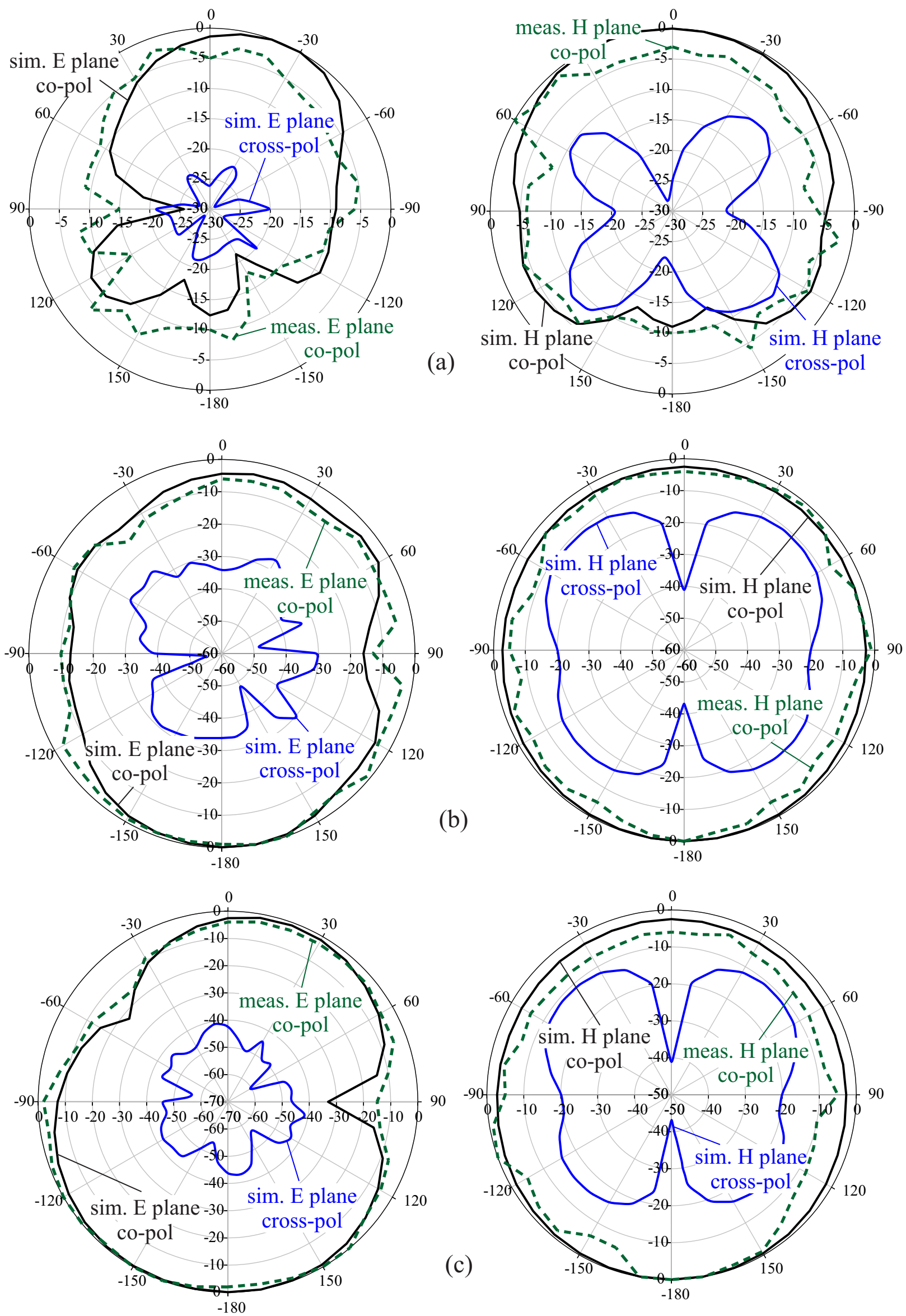

Fig. 3. The normalized radiation patterns at: (a) $-6.3 \mathrm{GHz}$, and (b) $-7.8 \mathrm{GHZ}$, and (c) $-10.4 \mathrm{GHz}$ 
Table 2. Earlier reported antennas in comparison with the proposed antenna

\begin{tabular}{lcccc}
\hline Reference & Volume $\left(\mathrm{mm}^{3}\right)$ & Bandwidth $(\mathrm{GHz})$ & Notch Band $(\mathrm{GHz})$ & Application \\
\hline$(1)$ & $32 \times 30 \times 1.6$ & $2.76-11$ & $3.45-4.8$ and $5.24-6.21$ & WiMAX and WLAN \\
$(2)$ & $30 \times 20 \times 1.5$ & $3.0-0.8$ & $3.4-3.8$ and $4.8-6.2$ & WiMAX and WLAN \\
$(3)$ & $38.1 \times 24.6 \times 1.5$ & $3-11$ & $3.3-3.7$ and $5.15-5.825$ & WiMAX and WLAN \\
$(4)$ & $44 \times 38 \times 1.57$ & 2.9 to more than 12 & $5.35-5.8$ and $7.98-8.85$ & WLAN and ITU \\
$(5)$ & $32 \times 24 \times 1.6$ & $2.7-11.6$ & $5.15-5.825$ and $7.25-7.75$ & WLAN and X \\
$(6)$ & $25 \times 25 \times 0.8$ & $2.97-12$ & $3.14-3.93$ and $4.9-6.07$ & WLAN and WiMAX \\
$(7)$ & $34 \times 30 \times 1$ & $2.8-12$ & $5.15-5.4$ and $5.75-6.0$ & WLAN \\
$(8)$ & $40.9 \times 34 \times 1$ & $2.90-12$ & $3.40-3.48$ and $5.40-5.98$ & WiMAX and WLAN \\
$(9)$ & $35 \times 28 \times 1.6$ & $2.2-19.5$ & $3.3-3.7$ and 5.15-5.85 & WiMAX and WLAN \\
$(10)$ & $25 \times 20 \times 1.14$ & $3.07-10.61$ & $3.41-3.68$ and $5.37-6.01$ & WiMAX and WLAN \\
This work & $24 \times 16 \times 1.58$ & $5.4-17.2$ & $6.9-7.4$ and $8.3-9.2$ & C and X band \\
\hline
\end{tabular}

\begin{tabular}{|c|}
\hline$J_{\text {surf }}(\mathrm{A} / \mathrm{m})$ \\
50.0 \\
42.9 \\
35.7 \\
28.6 \\
21.4 \\
14.3 \\
7.1 \\
0 \\
\hline
\end{tabular}
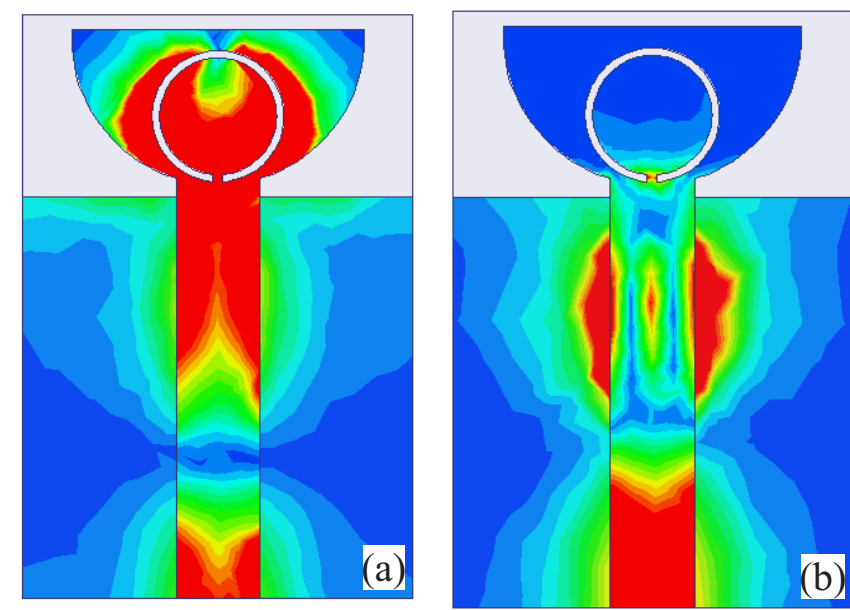

Fig. 4. The surface current (simulated) at (a) $7.2 \mathrm{GHz}$ and (b) $8.6 \mathrm{GHz}$

\section{Results}

The simulated and tested results of the proposed antenna are discussed in this section. The antenna is designed and simulated by the HFSS Ansoft software simulation tool.

The test results of the $S_{11}$ parameter are obtained by using a vector network analyzer of model no. ZNB 20. The $S_{11}$ parameter of the broadband antenna without notch elements and with notch elements is shown in Fig. 2(a). Simulated $S_{11}$ parameter provides $-10 \mathrm{~dB}$ impedance bandwidth from $5.4 \mathrm{GHz}$ to $17.4 \mathrm{GHz}$ with two rejection bands of $6.7-7.6 \mathrm{GHz}$ and $8.1-9.2 \mathrm{GHz}$ useful in $\mathrm{C}$ band and $\mathrm{X}$ band respectively. The open ring-type slot is responsible for the lower notch band and the $\mathrm{U}$ slot is responsible for the upper notch band. The obtained simulated peak notch frequencies are $7.0 \mathrm{GHz}$ and $8.6 \mathrm{GHz}$ for the lower notch band and upper notch band respectively. The simulated $S_{11}$ parameter values are $-1.9 \mathrm{dBi}$ and
$-1.19 \mathrm{dBi}$ at $7.0 \mathrm{GHz}$ and 8. $6 \mathrm{GHz}$ respectively. The measured $S_{11}$ parameter provides $-10 \mathrm{~dB}$ impedance bandwidth from $5.4 \mathrm{GHz}$ to $17.2 \mathrm{GHz}$ with two rejection bands of $6.9-7.4 \mathrm{GHz}$ and $8.3-9.2 \mathrm{GHz}$. The measured $S_{11}$ parameter shows that the lower notch band provides a $7.2 \mathrm{GHz}$ peak notch frequency with a $-2.4 \mathrm{~dB} S_{11}$ paramter value and the upper notch band provides an 8.6 $\mathrm{GHz}$ peak notch frequency with a $-3.27 \mathrm{~dB} S_{11}$ parameter value. There is a good parity between simulated and tested results for the $S_{11}$ parameter.

The gain plot of the wideband proposed antenna is shown in Fig. 2(b). The tested gain of $-2.5 \mathrm{dBi}$ and $-1.5 \mathrm{dBi}$ has been achieved at two notch frequencies of $7.2 \mathrm{GHz}$ and $8.6 \mathrm{GHz}$ respectively. The simulated antenna efficiency is plotted in Fig. 2(c). It appears that the antenna efficiencies reach $35 \%$ at $7.2 \mathrm{GHz}$ and $30 \%$ at 8.6 $\mathrm{GHz}$ of the notch bands. Otherwise, maximum radiation efficiency reaches $85 \%$ for the proposed antenna.

Radiation patterns ( $\mathrm{E}$ plane and $\mathrm{H}$ plane) at three different frequencies of $6.3 \mathrm{GHz}, 7.8 \mathrm{GHz}$, and $\mathrm{GHz}$ are 
plotted in Fig. 3. (a)-(c). The plots show monopole-like E plane radiation patterns and omnidirectional $\mathrm{H}$ plane radiation patterns.

Figure 4 depicts surface currents (simulated) at two peak notch frequencies of $7.2 \mathrm{GHz}$ and $8.6 \mathrm{GHz}$. At $7.2 \mathrm{GHz}$, maximum current occurs at feed line and lower portion of the patch, for $8.6 \mathrm{GHz}$ maximum current occurs at feed line and two sides of the feed line as shown in Fig. 4.

Table 2 compares the performance of the proposed antenna with the previously informed antennas. The proposed work provides good results in terms of size and operating bandwidth.

\section{Conclusions}

A broadband monopole antenna with two-band rejection characteristics is reported in this paper. The antenna achieves a bandwidth of $5.4 \mathrm{GHz}$ to $17.2 \mathrm{GHz}$. The lower notch band has been achieved by inserting an open ring slot on a metal patch whereas the $\mathrm{U}$ slot on the ground plane is responsible for the upper notch band. The reject bands cover a part of the $\mathrm{C}(6.6-7.6 \mathrm{GHz})$ band and a part of the $\mathrm{X}(8.2-9.2 \mathrm{GHz})$ band. The antenna achieves a peak notch gain of $-2.5 \mathrm{dBi}$ at $7.2 \mathrm{GHz}$. Radiation patterns are good and agreed with monopole antenna characteristics. The proposed antenna is useful for short-range and high-speed communication systems.

\section{REFERENCES}

[1] S. C Puri, S. Das, and M. G Tiary, "UWB monopole antenna with dual-band-notched characteristics", Microwave and Optical Technology Letters, 2019, 1-8.

[2] L. Y. Cai, Y. Li, G. Zeng, and H.C. Yang, "Compact wideband antenna with double-fed structure having band-notched characteristics", Electronics Letters 46, (2010).

[3] Guoping Gao, Lele He, Bin Hu, and Xiaodong Cong, "Novel dual band-notched UWB antenna with T-shaped slot and CSRR structure", Microwave and Optical Technology Letters, 57(2015), 1584-1590.

[4] M. Koohestani, N. Pires, A. K. Skrivervik and A. A. Moreira, "Band-reject ultra-wideband monopole antenna using patch loading", Electronics Letters, 48 (2012), 974-975.

[5] Y. Li, Wenxing Li, and R. Mittra, "Miniaturized CPW-fed UWB antenna with dual frequency rejection bands using stepped impedance stub and arc-shaped parasitic element", Microwave and Optical Technology Letters, 56(2014), 783-787.

[6] H. Li, L. Kang, D.-W. Mi, and Y.-Z. Yin, "Simple dual band-notched UWB antenna loaded with single U-shaped resonator", Microwave and Optical Technology Letters, 57 (2015), 2129-2134.

[7] X.-J. Liao, H.-C. Yang, N. Han and Y. Li, "UWB antenna with dual narrow band notches for lower and upper WLAN bands", Electronics Letters, 46 (2010), 1593.

[8] J. Liu, S. Gong, Y. Xu, X. Zhang, C. Feng, and N. Qi, "Compact printed Ultra-Wideband monopole antenna with dual band-notched characteristics", Electronics Letters, 44 (2008).

[9] G. Mishra and S. Sahu, "Nature inspired tree shaped antenna with dual band notch f or UWB applications", Microwave and Optical Technology Letters, 58 (2016), 1658-1661.

10] Y. Sung, "UWB monopole antenna with two notched bands based on the folded stepped impedance resonator", IEEE Antennas and Wireless Propagation Letters, 11 (2012).

Received 8 May 2021 